\title{
A RE-AIM evaluation of evidence-based multi- level interventions to improve obesity-related behaviours in adults: a systematic review (the SPOTLIGHT project)
}

Sofie Compernolle ${ }^{1 *}$, Katrien De Cocker ${ }^{1,2}$, Jeroen Lakerveld ${ }^{3}$, Joreintje D Mackenbach ${ }^{3}$, Giel Nijpels ${ }^{4}$, Jean-Michel Oppert ${ }^{5,6}$, Harry Rutter ${ }^{7}$, Pedro J Teixeira ${ }^{8}$, Greet Cardon ${ }^{1}$ and Ilse De Bourdeaudhuij ${ }^{1}$

\begin{abstract}
Background: This systematic literature review describes the potential public health impact of evidence-based multi-level interventions to improve obesity-related behaviours in adults, using the Reach, Efficacy, Adoption, Implementation and Maintenance (RE-AIM) framework.

Methods: Electronic databases (PubMed, Embase, and The Cochrane Library) were searched to identify intervention studies published between January 2000 and October 2013. The following inclusion criteria were used: (1) the study included at least one outcome measure assessing obesity-related behaviours (i.e. diet, physical activity or sedentary behaviour), (2) the study collected data over at least one year and (3) the study's intervention targeted adults, was conducted in a specified geographical area or worksite, and was multi-level (i.e. targeting both individual and environmental level). Evidence of RE-AIM of the selected interventions was assessed. Potential public health impact of an intervention was evaluated if information was provided on at least four of the five RE-AIM dimensions.

Results: Thirty-five multi-level interventions met the inclusion criteria. RE-AIM evaluation revealed that the included interventions generally had the potential to: reach a large number of people (on average $58 \%$ of the target population was aware of the intervention); achieve the assumed goals ( $89 \%$ found positive outcomes); be broadly adopted (the proportion of intervention deliverers varied from 9\% to 92\%) and be sustained (sixteen interventions were maintained). The highest potential public health impact was found in multi-level interventions that: 1) focused on all levels at the beginning of the planning process, 2) guided the implementation process using diffusion theory, and 3) used a website to disseminate the intervention.
\end{abstract}

Conclusions: Although most studies underreported results within the RE-AIM dimensions, the reported Reach, Effectiveness, Adoption, Implementation and Maintenance were positively evaluated. However, more information on external validity and sustainability is needed in order to take informed decisions on the choice of interventions that should be implemented in real-world settings to accomplish long-term changes in obesity-related behaviours.

Keywords: RE-AIM, Overweight, Obesity, Nutrition and physical activity interventions, Review

\footnotetext{
* Correspondence: sofie.compernolle@ugent.be

'Department of Movement and Sport Sciences, Faculty of Medicine and

Health Sciences, Ghent University, Ghent, Belgium

Full list of author information is available at the end of the article
} 


\section{Background}

The growing prevalence of overweight (Body Mass Index $\geq 25 \mathrm{~kg} / \mathrm{m}^{2}$ ) and obesity (Body Mass Index $\geq 30 \mathrm{~kg} / \mathrm{m}^{2}$ ) in adults is a major public health concern in European countries. Overweight and obesity contribute to mortality and the burden of many chronic diseases, such as cardiovascular diseases, cancer, type 2 diabetes and osteoarthritis [1-4]. Depending on country and gender, the overall prevalence of overweight in Europe currently ranges from 39.3\% (France) to $64.9 \%$ (England) in men and from 21.9\% (Italy) to $51.4 \%$ (England) in women. The overall prevalence of obesity ranges from $6.0 \%$ (France) to $21.6 \%$ (England) in men and from 5.0\% (Italy) to 23.3\% (England) in women [5]. In several European countries, adult obesity rates have doubled during the last two decades [6-8]. Given the serious health consequences and the rapidly increased prevalence, the development and implementation of effective, sustainable overweight and obesity prevention approaches is imperative.

In the past, several theoretical models have been used to develop overweight and obesity prevention approaches. Many of these approaches were informed by social psychological theories such as the Theory of Planned Behaviour [9], and the Transtheoretical Model [10], and were thus focused on health education and the modification of individual-level determinants of obesity-related behaviours (i.e. dietary, physical activity and sedentary behaviours) $[11,12]$. Athough these individual-based interventions have sometimes shown short-term effects, their long-term effectiveness is generally limited [12-14]. This could be explained by the fact that health behaviours are not solely a matter of individual determinants, but are also strongly affected by environmental factors [15-17]. Environmental factors are of growing importance with the development of increasingly 'obesogenic' environments in recent decades characterized by readily available, cheap, heavily advertised energy-dense foods, often provided with large portion sizes, and by reduced opportunities for physical activity accompanied by increased likelihood of sedentary behaviour, due to features such as urban sprawl, a lack of perceived safety and reductions in walkability [17-20]. These obesity-related environmental factors can be categorized using the Analysis Grid for Environments Linked to Obesity (ANGELO) framework [21]. This framework consist of two axes representing the size (micro vs. macro) and the type of the environment (i.e. socio-cultural, economic, political or physical environmental level).

Consequently, multi-level interventions that target both the individual level (e.g. by changing the beliefs, attitudes and knowledge of the participants) and at least one of the environmental levels as defined by the Analysis Grid for Environments Linked to Obesity (ANGELO) framework (i.e. socio-cultural, economic, political or physical environmental level) have shown promising results in counteracting obesity [11,14,22-24].

However, despite the increasing interest in multi-level interventions, little information is available on their characteristics, effectiveness and external validity [25]. Information on generalizability is essential to translate research findings into practice. To gain insight into both internal and external factors of health promotion interventions, Glasgow and colleagues developed the RE-AIM framework. This framework focuses on the five most important dimensions for evaluating the potential public health impact of programs intended for widescale implementation and dissemination. The framework covers the degree to which (1) an intervention reaches the target population, and to which degree the intervention participants are representative of the nonparticipants; (2) an intervention achieved the assumed goals, with optimal quality of life and without negative outcomes; (3) an intervention was broadly adopted, and to which degree both delivery setting and delivery staff were representative of non-deliverers; (4) an intervention was consistently implemented at a reasonable cost; and (5) an intervention had the ability to be sustained, with long-lasting individual effects [26].

The aim of the present study was to conduct a systematic review of multi-level interventions, aimed at reducing obesity-related behaviours in adults, as part of the European Commission funded "sustainable prevention of obesity through integrated strategies" (SPOTLIGHT) project [27]. The purpose of this review was to gain insight into 1) the characteristics of multi-level intervention, 2) the internal and external validity factors of multi-level interventions, and 3) the potential public health impact of multi-level interventions.

\section{Methods}

\section{Literature search}

A systematic literature search of three electronic databases (PubMed, Embase, The Cochrane Library) was conducted in April 2012, and updated in October 2013 to detect relevant intervention studies. The search strategy was developed using the PICO (participant, intervention, comparison, outcome) approach, and was limited to the English literature, published between January 2000 and October 2013. Details on the search strategy are listed in Additional file 1: Table S1.

After running the search strategy, duplicates were identified and removed. Subsequently, the studies were screened by title, abstract and full text to determine their eligibility by one reviewer (SC) and independently checked by a second reviewer (KDC). In addition, reference lists from the retrieved articles were examined for additional relevant intervention studies. 


\section{Inclusion criteria}

To be eligible, intervention studies had to meet the following inclusion criteria: (1) the study included at least one outcome measure assessing obesity-related behaviours (i.e. dietary, physical activity and sedentary behaviour); (2) the study collected data over at least one year; and (3) the study intervention was community-based, multi-level, and targeted adults. Interventions were considered community-based if they targeted a group of people that were mutually connected by the geographical area in which they were living or the worksite in which they were working. Interventions were considered multilevel, if they targeted at least one individual-level and at least one environmental-level determinant of obesityrelated behaviour. Environmental-level determinants were classified into four types based on the Analysis Grid for Environments Linked to Obesity (ANGELO) framework: physical environmental factors, socio-cultural environmental factors, economic environmental factors and political environmental factors.

\section{Data extraction}

As a result of the screening process, 35 interventions were selected. These are listed in Additional file 2, which presents information on the focus of the intervention (i.e. physical activity, sedentary behaviour or eating behaviour), study design, target population, study participants, intervention components, outcome measures and geographical area. Study design was divided into the categories of pre-experimental (one group pre-test post-test design and one group post-test only design) and experimental studies ((cluster) randomized controlled trials). As only multi-level interventions were included, the intervention components were split up into individual and environmental level components. Individual components aimed to change psychological factors, such as beliefs or knowledge (e.g. via information sessions, posters, etc.), while environmental components target the sociocultural (e.g. walking groups), economic (e.g. reduction of prices of healthy food items), political (e.g. the earning of physical activity points, which could be redeemed for paid leave) or physical environment of the participants (e.g. provision of cycling infrastructure). Outcome measures were considered in the categories of overweight and obesity-related behavioural outcomes (dietary behaviour, physical activity and sedentary behaviour) and obesity-related physiological outcomes (e.g. BMI, weight, fat percentage).

\section{RE-AIM evaluation}

The included interventions were evaluated on the basis of the RE-AIM framework [26]. Each of the five RE-AIM dimensions was divided into a number of indicators, and all included articles were coded by the first author on whether they reported on these specific indicators. A random selection of one third of the interventions was also coded by the second author to determine inter-rater reliability $(\mathrm{ICC}=0.81)$. Differences were discussed between the two assessors until full consensus was reached. The indicators for reach were: the description of the target population, awareness/participation rate, characteristics of people aware of the intervention and their representativeness. For effectiveness, we coded whether a study reported on positive outcomes, quality of life, negative outcomes and short-term attrition. Adoption was coded based on the following indicators: the proportion and representativeness of staff who delivered the intervention within the intervention delivery settings, and the proportion and representativeness of intervention delivery settings and non-delivery settings. Implementation was coded on completeness and fidelity of implementation and time, financial investment and staff expertise needed to implement the intervention. Maintenance was split up into individual level and organizational level maintenance. Individual level maintenance was based on whether information was reported on long term effectiveness, i.e. were outcomes reported at least six months after the completion of the intervention study: six months is a widely used time frame to assess behaviour change maintenance $[28,29]$. Organizational level maintenance was based on program sustainability, program adaptations and representativeness of settings/agents who were still delivering the interventions after the intervention study had been completed. If information was available on a specific indicator, data were extracted for further analysis. After the evaluation of each of the RE-AIM dimensions separately, the potential public health impact was assessed. Glasgow and colleagues state that the public health impact of an intervention depends on all five dimensions: reach, efficacy, adoption, implementation and maintenance. However in this review only three studies were included that reported on all five dimensions, so it was decided to lower the threshold from five to four dimensions: four studies reported on four dimensions. For each intervention, individual scores were calculated for reach (defined as the number of participants/number of eligible and invited people), efficacy (defined as the effect size of the intervention [30]), adoption (defined as the number of delivery settings/ number of eligible and invited settings), implementation (defined as consistency of delivering intervention components) and maintenance (defined as the number of settings that maintained the intervention after the initial phase/number of settings that stopped delivering the intervention). Subsequently, the RE-AIM average was calculated by summing the scores on the five RE-AIM dimensions (or four if only four dimensions were available), and dividing them by four or five. These RE-AIM averages were considered to reflect the 
potential public health impact of the interventions $[31,32]$.

\section{Results}

\section{Study characteristics}

Of the 14,002 studies identified in the literature search in April 2012, 126 studies remained after removing duplicates and screening titles and abstracts. The full texts of the remaining studies were evaluated for the inclusion criteria, which resulted in a final selection of 33 interventions, described in 70 papers [33-102]. In October 2013, an update was conducted, which yielded another two interventions $[103,104]$. Consequently, 35 interventions were included in the systematic review. The flow chart in Figure 1 describes the entire selection process.

The characteristics of the identified studies are described in Additional file 2 and summarized in Table 1. The majority (69\%) of the interventions were assessed by a cluster-randomized controlled trial [36-39,41,44,47,49, $51-53,55,63,74,76,79-82,90,91,103]$. Of the studies using a pre-experimental design (31\%), $82 \%$ used a one group pretest posttest design without control group [35,50,60, $67,75,87,93,100,102,104]$ and $18 \%$ used a one group only posttest design $[68,92]$. Different methods for data collection were used throughout the studies. In 32 studies
$[6,35-39,41,44,47,49-53,55,60,67,68,74,75,79-82,87,91$ $93,99,100,102-104]$, participants had to fill out a questionnaire to evaluate levels of physical activity and sedentary behaviour $(\mathrm{n}=25)$, food intake $(\mathrm{n}=19)$, knowledge on health and health-related behaviours $(\mathrm{n}=8)$, psychosocial variables $(n=9)$ or awareness of/attendance at the intervention $(n=9)$. Two studies [44,51] utilized pedometers objectively to monitor levels of physical activity, and one study used direct observations to evaluate obesityrelated behaviours. In 15 studies [35,36,47,51-53,55, $61,64,74,79,84,87,91,104]$ clinical measurements were performed to determine overweight and obesity-related physiological outcomes, such as weight, height, blood pressure, waist circumference etc. The most commonly implemented individual-level intervention components were educational sessions $(n=11)$, individual counselling and advice on obesity-related behaviours $(n=9)$, posters $(\mathrm{n}=8)$ and newsletters $(\mathrm{n}=8)$. Other components were leaflets, websites, pedometers, logbooks, motivational messages, food and cooking demonstrations, education tours in supermarkets, maps with physical activity possibilities, individual feedback on clinical measurements and food labeling. The most commonly implemented environmental components were the establishment of walking and cycling groups $(\mathrm{n}=14)$, the organization of physical

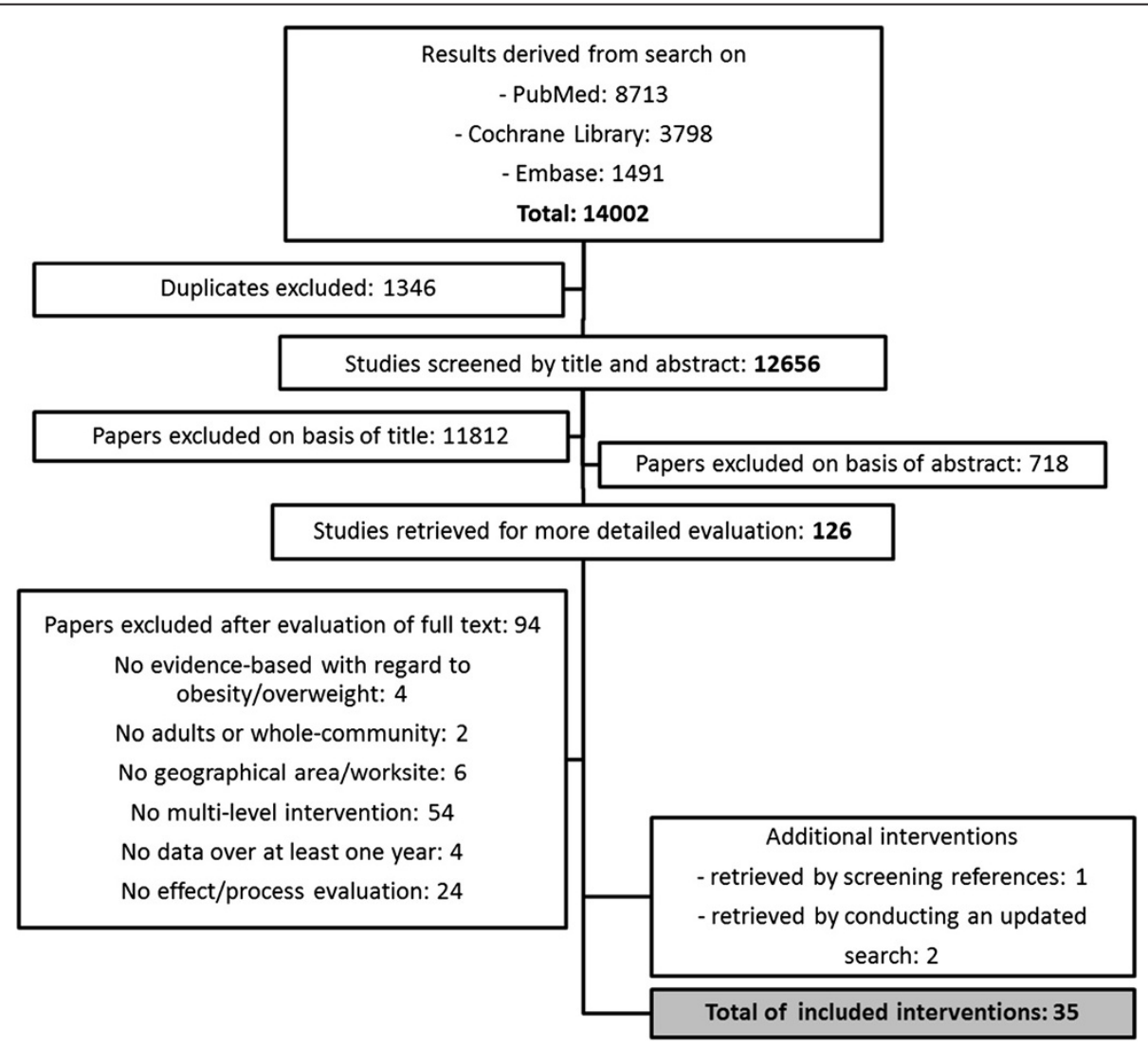

Figure 1 Flow chart of study selection process. Figure 1 provides an overview of the study selection process. 
Table 1 Characteristics of identified studies

\begin{tabular}{ll}
\hline Study characteristics & No. studies (\%) \\
\hline Design & \\
Quasi-experimental design & $70 \%$ \\
Pre-experimental design & $30 \%$ \\
Focus & \\
Combination physical activity, sedentary & \\
behaviour and eating behaviour & $57 \%$ \\
Physical activity & \\
Sedentary behaviour & $33 \%$ \\
Eating behaviour & $0 \%$ \\
Setting & $9 \%$ \\
Schools/workplaces & \\
Churches & $27 \%$ \\
Communities & $12 \%$ \\
Participants & $61 \%$ \\
$>1000$ in at least one measurement & \\
$>1000$ in all measurements & $69 \%$ \\
Data collection method & $38 \%$ \\
Questionnaire & \\
Clinical measures & \\
Pedometers & \\
Geographical area & $91 \%$ \\
America & $39 \%$ \\
Europe & $6 \%$ \\
Asia & \\
\hline & \\
\hline
\end{tabular}

activity group sessions $(\mathrm{n}=13)$ and the increase of available healthy foods $(n=12)$. Other environmental intervention components were social support, the improvement of walking/cycling paths, the loan of pedometers, the increase of the number of physical activity areas and improved accessibility, the organization of health/physical activity events, the start of a physical activity competition, the reduction of prices of healthy food items, etc.

\section{RE-AIM evaluation}

Thirty-two interventions did not report on all five dimensions. More than one-third of the selected interventions $(15 / 35)$ only provided information on the degree of effectiveness. Eight interventions confined themselves to the report of two dimensions, namely the reach and the effectiveness. Another eight interventions, reported on three dimensions, of which four reported on the effectiveness, the adoption and the implementation, three reported on the reach, the effectiveness and the adoption and one intervention reported on the reach, the effectiveness and the implementation. This left us with only four interventions that gave information on at least four of the five RE-AIM dimensions.

Table 2 presents the main results regarding the report on Reach, Effectiveness, Adoption, Implementation and Maintenance of the included interventions. Details of the information extracted from the intervention studies are provided in the paragraphs below (see Additional file 3).

\section{Reach}

All studies described the target population of the intervention. Two interventions (6\%) reported specific inclusion criteria, while all other interventions targeted the whole

Table 2 Number of studies reporting on the different RE-AIM dimensions

\begin{tabular}{|c|c|}
\hline Component & $\begin{array}{l}\text { Number of studies } \\
\text { reporting } \mathbf{n}(\%)\end{array}$ \\
\hline \multicolumn{2}{|l|}{ Reach } \\
\hline $\begin{array}{l}\text { - Description of target population within the } \\
\text { geographical area/worksite }\end{array}$ & $33(100)$ \\
\hline - Awareness of the intervention/participation rate & $16(48)$ \\
\hline $\begin{array}{l}\text { - Characteristics of people aware of the } \\
\text { intervention/participants }\end{array}$ & $10(30)$ \\
\hline $\begin{array}{l}\text { - Representativeness of people aware of the } \\
\text { intervention/participants }\end{array}$ & $9(27)$ \\
\hline \multicolumn{2}{|l|}{ Effectiveness } \\
\hline - Positive outcomes & $30(91)$ \\
\hline - Quality of life & $1(3)$ \\
\hline - Negative consequences & $1(3)$ \\
\hline - Short-term attrition & $15(43)$ \\
\hline \multicolumn{2}{|l|}{ Adoption } \\
\hline - Description of staff delivering the intervention & $6(17)$ \\
\hline $\begin{array}{l}\text { - Representativeness of staff delivering the } \\
\text { intervention }\end{array}$ & $1(3)$ \\
\hline - Description of intervention delivery settings & $23(70)$ \\
\hline - Description of non-delivering settings & $5(15)$ \\
\hline - Representativeness of delivery settings & $3(9)$ \\
\hline \multicolumn{2}{|l|}{ Implementation } \\
\hline - Completeness of implementation & $10(30)$ \\
\hline - Fidelity of implementation & $2(6)$ \\
\hline - Time needed to implement the intervention & $0(0)$ \\
\hline - Financial investment of the intervention & $8(24)$ \\
\hline - Staff expertise of training of the deliverers & $4(12)$ \\
\hline \multicolumn{2}{|l|}{ Maintenance - setting } \\
\hline - Program sustainability & $8(24)$ \\
\hline - Program adaptations & $3(9)$ \\
\hline $\begin{array}{l}\text { - Representativeness of organizations who are } \\
\text { still delivering the intervention }\end{array}$ & $1(3)$ \\
\hline \multicolumn{2}{|l|}{ Maintenance - individual } \\
\hline - Long-term effects & $8(23)$ \\
\hline
\end{tabular}


(adult) community/all employees. The number of people belonging to the target group was reported in 17 studies (49\%) and varied from 500 to $37,000,000$ people. Almost half of the studies $(46 \%)$ gave information on the number of people affected by the intervention. The participation level of some intervention components could not be determined (e.g. improving street lightning, renovating walking paths, handing out flyers, putting up posters) so both awareness rates and participation rates were discussed. The mean awareness rate was $58 \%$. Three studies $[49,56,91]$ reported awareness rates above $90 \%$, while one study [82] reported an awareness rate of less than $20 \%$. In contrast to the high awareness rates, the mean participation rate in at least one activity was $30 \%$ and ranged from $1 \%$ in "Walk Kansas" [50] to 94\% in "Body and Soul" [42]. The representativeness of people who were aware of the intervention/intervention participants was described in nine studies (26\%). Of these nine studies, two found no significant differences, while seven observed significant differences by sex $(n=5$; women were more likely to participate), age ( $n=2$; older people were more likely to participate), physical activity level $(\mathrm{n}=2$; active people were more likely to participate), $\mathrm{BMI}(\mathrm{n}=1$; people with a higher BMI were more likely to participate) and ethnicity $(\mathrm{n}=1$; Western people were more likely to participate) between participants and non-participants.

\section{Effectiveness}

Nearly all intervention studies (89\%) recorded positive obesity-related behavioural $(71 \%)$ or overweight and obesity-related physiological outcomes (34\%). Of the studies reporting positive behavioural outcomes, seventeen reported on physical activity or sedentary behaviour, while thirteen studies reported on dietary behaviour. One study [102] notified a negative outcome and one study reported quality of life data [80]. Information on percent attrition was provided in fifteen studies, ranging from 4-85\%.

\section{Adoption}

Adoption of interventions was reported in all studies. At the staff level, six interventions described the intervention agents. Of these, five studies reported the number of intervention agents, ranging from 1-176, and five studies provided information on the characteristics of intervention agents. Only one study analysed the representativeness of intervention agents [97]. This analysis indicated that women and those with more years of experience of PA promotion are more likely to adopt the program than men and those with less experience of PA promotion. No significant differences were found in mean age between intervention agents and non-project staff members [97].

At the setting level, all the studies reported information on the delivery settings. Interventions were delivered in churches $(n=4)$, schools $(n=2)$, worksites $(n=8)$ and communities $(n=21)$. The number of delivery settings was reported in all worksite, school-based and churchbased interventions, while only $50 \%$ of the communitybased interventions gave information on the number of different delivery settings. The proportion of delivery settings was presented in $23 \%$ of the studies, and ranged from 9\% (NHF-NRG In Balance [63]) to 92\% (Walk Kansas [50]). Information on non-delivering settings was presented in $14 \%$ of the studies. Three studies compared the delivery setting with the non-delivery settings to work out their representativeness. This comparison showed significant differences between delivery settings and non-delivery settings in "Walk Kansas" and "Health-e-AME". Both studies demonstrated that larger communities were more likely to adopt the intervention. No significant differences were found between deliverer settings and non-delivery settings in the intervention "10.000 Steps Flanders".

\section{Implementation}

Within implementation, the report of five items was evaluated. Completeness of implementation was reported in ten studies (29\%). Three of these studies (10.000 Steps Flanders, Healthworks and Health-e-AME) gave a separate implementation score per intervention component. This implementation score reflected the percentage of intervention delivering settings that implemented a specific intervention component. In "10,000 Steps Flanders", the implementation score varied from $17 \%$ for wideranging personal contact with citizens to $91 \%$ for the loan and sale of pedometers. "Healthworks" succeeded in implementing the offering of healthy food, the promotion of walking, the loan of pedometers, the dissemination of a newsletter and the promotion of stair use, but failed in achieving a reduction in healthy food prices. The implementation score of "Health-e-AME" components ranged from 7/50 for " 8 Steps to Fitness" to 16/50 for the walking program. Reasons given for not implementing intervention components included 'no time', 'too expensive', no space', 'no added value for the project', 'not relevant to our core business', and 'lack of information to implement the component'. One study [64] ascribed the failure of implementation to external factors, such as vending drivers and food service managers, preventing food prices from being reduced due to concerns about possible adverse economic consequences. Fidelity of implementation was reported in two studies (6\%), of which one [101] reported the adherence to program principles by component. None of the intervention studies reported time needed to implement the intervention; eight (23\%) did not report financial investment of the organization, and four (11\%) did not report staff expertise/training. Of the eight studies reporting on financial investment, seven emphasized the low costs for organizations, because they were sponsored by 
external grants, which varied from $€ 27,000$ (Elementary School Personnel Intervention [91]) to $€ 900,000$ (Hartslag Limburg [84]).

\section{Maintenance}

Maintenance was subdivided by Glasgow et al. into the individual level maintenance and organizational level maintenance [26]. At the individual level, eight interventions reported their health behaviour at least six months beyond the study period. Of these, all studies found long-term effects. At the organizational level, to our knowledge, sixteen interventions were sustained until October 2013. Nevertheless, only eight studies explicitly described the continuation or dissemination of the intervention after the intervention study. Three studies evaluated the dissemination of the intervention and three studies reported on adaptations. The interventions "10,000 steps Flanders" [44] and "Agita São Paulo" [68] were not adapted after dissemination of the intervention, while "10,000 steps Rockhampton" [49] adapted the intervention through a website.

\section{Potential public health impact}

As mentioned above, the potential public health impact of four interventions was assessed (see Figure 2). Three of them provided information on all five dimensions: Walk Kansas (USA) [50], 10,000 Steps Flanders (Belgium) [44], and Health-e-AME (USA) [101], while one intervention provided information on four out of five dimensions: Body and Soul (USA) [81]. Both "Walk Kansas" and "10,000 Steps Flanders" were community-based physical activity programs, whereas the "Health-e-AME" intervention and the "Body and Soul" intervention were church-based interventions, focusing on physical activity and dietary behaviour, respectively. In "Walk Kansas", participants formed a team and each team was supposed to identify a physical activity-related goal it wanted to reach. In "10,000 Steps Flanders", several physical activity intervention components were implemented based on the central theme of reaching 10,000 steps/day. In "Health-e-AME, physical activity-related intervention components were implemented based on the Social Ecological Theory, and the Transtheoretical model, and in "Body and Soul", intervention components related to healthy eating were implemented. When judging the potential public health impact of those four interventions by calculating the average RE-AIM score, the "Health-e-AME" intervention scored the lowest based on limited positive effects. Moreover, the different intervention components of the "Health-e-AME" intervention program were inconsistently implemented. This fragmented implementation was also observed for the "Body and Soul" intervention, in which only one out of eight intervention churches initiated all four pillars. In contrast, "10,000 Steps Flanders" noticed a modest global implementation score and "Walk Kansas" emphasized the consistent implementation of key intervention components. In spite of this, it cannot be presumed that " 10,000 Steps Flanders" and "Walk Kansas" have a higher potential public health impact than "Health-e-AME" and "Body and Soul", due to the restricted adoption rate of "10,000 Steps Flanders" (36\%), and the limited participation rate of "Walk Kansas" (1\%). Besides the adoption and participation rate, representativeness of participants and intervention agents was judged. In "10,000 Steps Flanders" no significant differences were found between participants and non-participants, whereas "Walk Kansas" and "Healthe-AME" identified that women were more likely to participate than men. In addition, "Walk Kansas" seemed more appealing for people who are already active, compared to non-active people. All four interventions found significant differences in representativeness of intervention deliverers: "10,000 Steps Flanders" concluded that staff members with longer experience of physical activity promotion were more likely to adopt the programme; "Health-e-AME" concluded that larger churches are more likely to adopt the programme; "Body and Soul" noticed that intervention deliverers were likely to have higher educational status and a higher income than non-deliverers. "Walk Kansas" was more often adopted by counties with higher populations. Sustainability was extensively discussed in three interventions: "10,000 Steps Flanders", "Health-e-AME", and "Walk Kansas". "Walk Kansas" scored best, since $76 \%$ of the counties adopted the intervention for at least three years. Consequently, based on the RE-AIM evaluation, it can be concluded that "Walk Kansas" achieved the highest potential public health impact, in spite of its low participation rate.

\section{Discussion}

The aim of this review was to provide an overview of the existing evidence-based multi-level interventions to improve obesity-related behaviours, and to determine their Reach, Effectiveness, Adoption, Implementation and Maintenance in order to assess their potential public health impact.

A total of 35 multi-level interventions were identified, described and assessed on the five RE-AIM dimensions. Typically, multi-level interventions are not evaluated using randomized controlled trials. This is due to the fact that multi-level interventions have components that cannot be individually randomized (e.g. environmental changes) and represent real-world settings. Despite their limitations conducting trials in real world settings provides information on whether an intervention works under usual conditions, which facilitates research translation [105].

Concerning the report of RE-AIM dimensions, the results showed that information was largely underreported, 


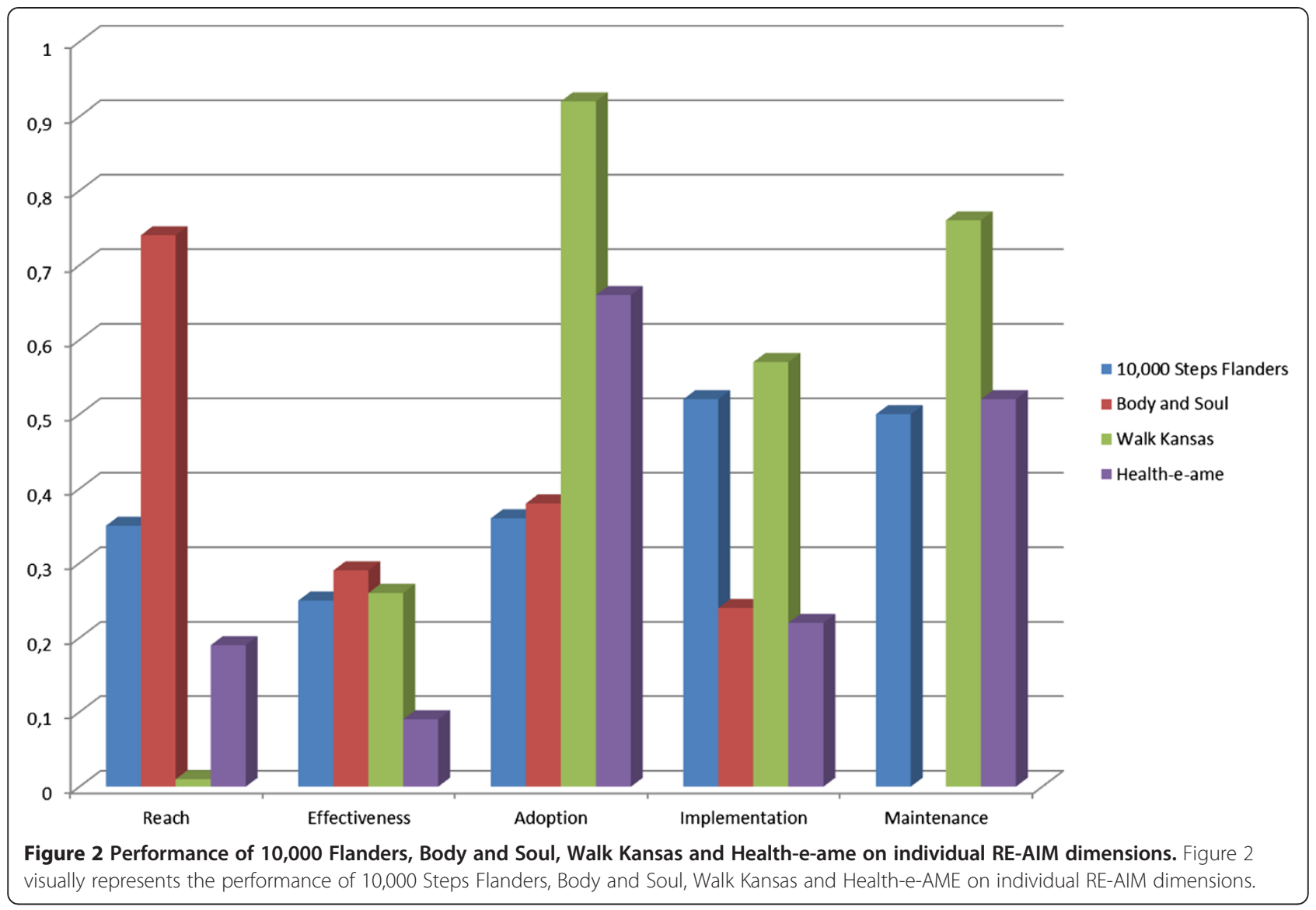

with description of elements of external validity and generalizability especially lacking. This finding is in line with the results of previous reviews [106-112] and hampers the assessment of potential public health impact, which is needed to determine if an intervention should be implemented and disseminated on a large scale.

Our findings on reach of the interventions are in accordance with the results reported in previous reviews [25,106-109]. As observed in the review of Vuillemin et al. [109], all studies described the intended target audience. This description was generally not very detailed, since the majority of the multi-level interventions were community-based, in which all members of the population were considered eligible. This is particularly relevant since people with health conditions are often omitted from experimental research $[26,106,113]$. Other aspects of reach were less frequently reported, although these aspects are important for assessing the external validity of the interventions. Only $46 \%$ of the studies provided information on the numbers of individuals actually reached, which is relatively low in comparison with the results of other reviews [106-108]. Overall participation rates were highest in church-based interventions, and lowest in community-based interventions. Furthermore, over half the studies declared that women were more likely to participate than men. Consequently, it seems that most of the obesity prevention approaches were less appealing to, or less adapted to the needs of, men rather than women.

In terms of Effectiveness of the interventions, positive overweight and obesity-related behavioural and, physiological outcomes are the most consistently reported aspects within the RE-AIM framework. However, these positive outcomes could be overestimated, since the majority of the studies did not account for attrition. Furthermore, negative outcomes of the intervention, and effects on quality of life are rarely reported, which is in agreement with the results of Dzewaltowksi et al. and Antikainen et al. [106,107]. Nonetheless, other reviews have identified higher percentages for reports of adverse consequences $(30 \%-32 \%)[108,109]$. The unbalanced relation in reporting positive and negative outcomes may be due to publication bias. However, knowledge on adverse effects is highly important for large-scale implementation and dissemination [26].

Regarding the Adoption of the interventions, similar to previous reviews [109,110], information on intervention agents was underreported. In contrast, the number of delivery settings was widely reported $[106,108,109]$. Unfortunately, this number provides insufficient information to 
assess the generalizability of an intervention. Therefore, our focus was on the adoption rate, which refers to the proportion of participating settings. The adoption rate was highest in "Walk Kansas". However, "Walk Kansas" was developed based on strategies and principles about feasible implementation methods, whereas most other programs were developed simply and solely with attention to efficacy. Furthermore, most of the interventions describe the characteristics of the intervention deliverers, but only $14 \%$ of the interventions reported on characteristics of non-deliverers, which is comparable with the results of earlier reviews [106-109]. Consequently, information is lacking to assess the representativeness of the interventions, so no meaningful conclusions could be drawn with respect to the external validity of the interventions.

The first two aspects of implementation of the interventions - 'completeness' and 'fidelity' - are important to judge the internal validity of interventions and to assess the appropriateness of the interventions' conclusions. In addition, reporting on the consistency of intervention components provides information on the degree of ease for implementing different components. Unfortunately, despite the relatively high number reporting on completeness or fidelity of implementation, the information was largely incomplete. Moreover, the ways of providing information on completeness varied considerably, so no comparison could be made between the interventions. Nonetheless, when looking at the reasons for not implementing intervention components, it can be concluded that intervention components need to be low-cost, timeefficient and suitable for organizations or communities with limited space. Moreover, the role of external factors needs to be reduced to a minimum so that the prosperity of an intervention component is independent of external factors. Furthermore, financial investment, time and expertise needed to implement the intervention were investigated in order to estimate the load for the intervention agents. Unlike previous reviews [108,109], only financial investment was extensively reported. However, it seems that the majority of the interventions were funded by external grants, so that no additional costs were required from the intervention deliverers.

Only eight intervention studies included information on maintenance in the form of programme sustainability, in spite of the continuation of sixteen interventions. However, this is a favourable result, compared to the results of previous reviews, in which programme sustainability varied between $0 \%$ and $5 \%[106,108,109]$. Nevertheless, it should be acknowledged that all the included interventions were introduced in the last thirteen years, whereby the sustainability of the interventions is relative. Furthermore, it is notable that community -and church based interventions are more likely to be proceeded, than worksite -and school based interventions, which is in line with the results of Antikainen et al. [106]. They stated that all the studies that reported on institutional level maintenance were community-based interventions that focused on translating an intervention into a real-world setting.

Finally, the potential public health impact of four interventions that reported on at least four RE-AIM dimensions was evaluated. This evaluation was based on the RE-AIM average score defined by Glasgow et al. [31]. This score did not contain information on all aspects within the RE-AIM dimensions, whereby the score should be interpreted with caution. Of the four interventions $[37,44,50,81]$, our findings suggest that "Walk Kansas" scored highest for potential public health impact. An important clarification for the high score of "Walk Kansas", is that all levels were included, from potential program participants to organizational sponsors, at the beginning of the planning process. This resulted in an attractive program both for community members and programme deliverers. Moreover, in both "Walk Kansas" and "10,000 Steps Flanders", the diffusion theory was used to guide the implementation process, which was defined as 'the process by which an innovation is communicated through certain channels over time among the members of a social system' [114]. Furthermore, both interventions used a website to inform potential participants, and to disseminate the intervention.

\section{Conclusions}

The majority of the obesity-related multi-level intervention that we identified have the potential to reach a large amount of people, including those who can benefit most. Moreover, it seems that multi-level interventions are likely to be broadly adopted and to be sustained. RE-AIM assessment showed that multi-level interventions that 1) focused on all levels, from potential program participants to organizational sponsors, at the beginning of the planning process, 2) applied the diffusion theory to guide the implementation process, and 3) used a website to disseminate the intervention, achieved the highest potential public health impact. Nevertheless, better reporting of factors related to external validity and sustainability is needed to confirm these results.

\section{Additional files}

Additional file 1: Search strategy. Search strategy, existing of keywords used for inclusion, and keywords used for exclusion.

Additional file 2: Characteristics of the included studies.

Characteristics of the identified studies, including information on the focus of the intervention, study design, target population, study participants, intervention components, outcome measures and geographical information.

Additional file 3: RE-AIM evaluation. Reach, Effectiveness, Adoption, Implementation and Maintenance of the included interventions. 


\section{Abbreviations}

RE-AIM: Reach, Effectiveness, Adoption, Implementation, Maintenance.

\section{Competing interests}

The authors declare that they have no competing interests.

\section{Authors' contributions}

$J \mathrm{~L}, \mathrm{IDB}$ and SC conceived of the idea for the review. IDB wrote the protocol and led the writing of the manuscript. KDC checked the eligibility of the included intervention studies and performed data extraction. JDM assessed methodological quality of the included interventions studies. All authors read, provided feedback, and approved the final submitted version of the manuscript.

\section{Acknowledgements}

This work is part of the SPOTLIGHT project funded by the Seventh Framework Programme (CORDIS FP7) of the European Commission, HEALTH (FP7-HEALTH-2011-two-stage), Grant agreement no. 278186. The content of this article reflects only the authors' views and the European Commission is not liable for any use that may be made of the information contained therein.

\section{Author details}

'Department of Movement and Sport Sciences, Faculty of Medicine and Health Sciences, Ghent University, Ghent, Belgium. ${ }^{2}$ Research Foundation Flanders (FWO), B-1000 Ghent, Belgium. ${ }^{3}$ The EMGO Institute for Health and Care Research, Department of Epidemiology and Biostatistics, VU University Medical Center, Amsterdam, The Netherlands. ${ }^{4}$ The EMGO Institute for Health and Care Research, Department of General Practice and Elderly Care Medicine, VU University Medical Center, Amsterdam, The Netherlands. ${ }^{5}$ Université Paris 13, Sorbonne Paris Cité - UREN (Unité de Recherche en Epidémiologie Nutritionnelle), U557 Inserm; U1125 Inra; Cnam, Centre for Research on Human Nutrition Ile-de-France (CRNH IdF), Bobigny, France. ${ }^{6}$ Université Pierre et Marie Curie-Paris 6, Department of Nutrition Pitié-Salpêtrière Hospital (AP-HP), (CRNH IdF), Institute of Cardiometabolism and Nutrition (ICAN), Paris, France. ${ }^{7}$ European Centre on Health of Societies in Transition, London School of Hygiene and Tropical Medicine, London, UK. ${ }^{8}$ Interdisciplinary Center for the Study of Human Performance, Faculty of Human Kinetics, University of Lisbon, Lisbon, Portugal.

Received: 13 December 2013 Accepted: 17 November 2014

Published online: 06 December 2014

\section{References}

1. Branca F, Nikogosian H, Lobstein T: The Challenge of Obesity in the WHO European Region and the Strategies for Response. ; 2007.

2. Dennis KE: Postmenopausal women and the health consequences of obesity. J Obstet Gynecol Neonatal Nurs 2007, 36:511-517. quiz 518-519.

3. Kopelman P: Health risks associated with overweight and obesity. Obes Rev 2007, 8(Suppl 1):13-17.

4. Must A, Spadano J, Coakley EH, Field AE, Colditz G, Dietz WH: The disease burden associated with overweight and obesity. JAMA 1999, 282:1523-1529.

5. Roskam AJ, Kunst AE, Van Oyen H, Demarest S, Klumbiene J, Regidor E, Helmert U, Jusot F, Dzurova D, Mackenbach JP: Comparative appraisal of educational inequalities in overweight and obesity among adults in 19 European countries. Int J Epidemiol 2010, 39:392-404.

6. OECD: Overweight and obesity among adults. In Health at a Glance: Europe 2012. 2012:62-64.

7. Finucane MM, Stevens GA, Cowan MJ, Danaei G, Lin JK, Paciorek CJ, Singh GM, Gutierrez HR, Lu Y, Bahalim AN, Farzadfar F, Riley LM, Ezzati M: National, regional, and global trends in body-mass index since 1980: systematic analysis of health examination surveys and epidemiological studies with 960 country-years and 9.1 million participants. Lancet 2011 377:557-567.

8. Stevens GA, Singh GM, Lu Y, Danaei G, Lin JK, Finucane MM, Bahalim AN, McIntire RK, Gutierrez HR, Cowan M, Paciorek CJ, Farzadfar F, Riley L, Ezzati $\mathrm{M}$ : National, regional, and global trends in adult overweight and obesity prevalences. Popul Health Metr 2012, 10:22.
9. Ajzen I: From intentions to actions: A theory of planned behavior. In Action Control. Edited by Kuhl J, Beckmann J. Berlin Heidelberg: Springer; 1985:11-39. SSSP Springer Series in Social Psychology.

10. Marcus BH, Simkin LR: The transtheoretical model: applications to exercise behavior. Med Sci Sports Exerc 1994, 26:1400-1404.

11. Bauman AE, Reis RS, Sallis JF, Wells JC, Loos RJ, Martin BW: Correlates of physical activity: why are some people physically active and others not? Lancet 2012, 380:258-271.

12. Spence JC, Lee RE: Toward a comprehensive model of physical activity. Psychol Sport Exerc 2003, 4:7-24.

13. Giles-Corti B, Donovan RJ: Relative influences of individual, social environmental, and physical environmental correlates of walking. Am J Public Health 2003, 93:1583-1589.

14. Robertson A, Lobstein T, Knai C: Obesity and socio-economic groups in Europe: Evidence review and implications for action. [http//www.scpknowledge.eu/ knowledge/obesity-and-socio-economic-groups-europe-evidence-review-andimplications-action]

15. Canoy D, Buchan I: Challenges in obesity epidemiology. Obes Rev 2007, 8(Suppl 1):1-11.

16. Hill JO, Wyatt HR, Reed GW, Peters JC: Obesity and the environment: where do we go from here? Science 2003, 299:853-855.

17. Owen N, Leslie E, Salmon J, Fotheringham MJ: Environmental determinants of physical activity and sedentary behavior. Exerc Sport Sci Rev 2000, 28:153-158.

18. Giskes K, van Lenthe F, Avendano-Pabon M, Brug J: A systematic review of environmental factors and obesogenic dietary intakes among adults: are we getting closer to understanding obesogenic environments? Obes Rev 2011, 12:e95-e106.

19. Peters JC: The challenge of managing body weight in the modern world. Asia Pac J Clin Nutr 2002, 11(Suppl 8):S714-S717.

20. Fabricatore AN, Wadden TA: Obesity. Annu Rev Clin Psychol 2006, 2:357-377.

21. Glass TA, McAtee MJ: Behavioral science at the crossroads in public health: extending horizons, envisioning the future. Soc Sci Med 2006, 62:1650-1671.

22. Huang TT, Drewnosksi A, Kumanyika S, Glass TA: A systems-oriented multilevel framework for addressing obesity in the 21 st century. Prev Chronic Dis 2009, 6:A82.

23. Maclean LM, Clinton K, Edwards N, Garrard M, Ashley L, Hansen-Ketchum P, Walsh A: Unpacking vertical and horizontal integration: childhood overweight/obesity programs and planning, a Canadian perspective. Implement Sci 2010, 5:36.

24. De Bourdeaudhuij I, Van Cauwenberghe E, Spittaels H, Oppert JM, Rostami C, Brug J, Van Lenthe F, Lobstein T, Maes L: School-based interventions promoting both physical activity and healthy eating in Europe: a systematic review within the HOPE project. Obes Rev 2011, 12:205-216.

25. Riley BL, MacDonald J, Mansi O, Kothari A, Kurtz D, VonTettenborn LI, Edwards NC: Is reporting on interventions a weak link in understanding how and why they work? A preliminary exploration using community heart health exemplars. Implement Sci 2008, 3:27.

26. Glasgow RE, Vogt TM, Boles SM: Evaluating the public health impact of health promotion interventions: the RE-AIM framework. Am J Public Health 1999, 89:1322-1327.

27. Lakerveld J, Brug J, Bot S, Teixeira PJ, Rutter H, Woodward E, Samdal O, Stockley L, De Bourdeaudhuij I, van Assema P, Robertson A, Lobstein T, Opper JM, Ádány R, Nijpels G, and on behalf of the SPOTLIGHT consortium: Sustainable prevention of obesity through integrated strategies: The SPOTLIGHT project's conceptual framework and design. BMC Public Health 2012, 12:793.

28. Prochaska JO, Velicer WF: The transtheoretical model of health behavior change. Am J Health Promot 1997, 12:38-48.

29. Allen K, Zoellner J, Motley M, Estabrooks PA: Understanding the internal and external validity of health literacy interventions: a systematic literature review using the RE-AIM framework. J Health Commun 2011, 16:55-72.

30. Hedges L: Distribution theory for Glass's estimator of effect size and related estimators. J Educ Statistics 1981, 6:128.

31. Glasgow RE, Klesges LM, Dzewaltowski DA, Estabrooks PA, Vogt TM: Evaluating the impact of health promotion programs: using the RE-AIM framework to form summary measures for decision making involving complex issues. Health Educ Res 2006, 21:688-694.

32. Glasgow RE, Nelson CC, Strycker LA, King DK: Using RE-AIM metrics to evaluate diabetes self-management support interventions. Am J Prev Med 2006, 30:67-73. 
33. UNC Center for Health Promotion and Disease Prevention: Intervention: Arkansas Healthy Employee Lifestyle Program (AHELP). [http://www. centertrt.org/?p=intervention\&id=1106]

34. Allicock M, Campbell MK, Valle CG, Carr C, Resnicow K, Gizlice Z: Evaluating the dissemination of Body \& Soul, an evidence-based fruit and vegetable intake intervention: challenges for dissemination and implementation research. J Nutr Educ Behav 2012, 44:530-538.

35. Ayala GX: Effects of a promotor-based intervention to promote physical activity: Familias Sanas y Activas. Am J Public Health 2011, 101:2261-2268.

36. Bell AC, Swinburn BA, Amosa H, Scragg RK: A nutrition and exercise intervention program for controlling weight in Samoan communities in New Zealand. Int J Obes Relat Metab Disord 2001, 25:920-927.

37. Bopp M, Wilcox S, Laken M, Hooker SP, Saunders R, Parra-Medina D, Butler K, McClorin L: Using the RE-AIM framework to evaluate a physical activity intervention in churches. Prev Chronic Dis 2007, 4:A87.

38. Boshtam M, Sarafzadegan N, Zare K, Sadeghi S, Sajjadi F, Rabiei K, Boshtam $M$ : Effects of 5-year interventions on cardiovascular risk factors of factories and offies employees of isfahan and najafabad: worksite intervention project-isfahan healthy heart program. ARYA Atheroscler 2010, 6:94-101.

39. Bowen DJ, Beresford SA, Christensen CL, Kuniyuki AA, McLerran D, Feng Z, Hart A Jr, Tinker L, Campbell M, Satia J: Effects of a multilevel dietary intervention in religious organizations. Am J Health Promot 2009, 24:15-22.

40. Brownson RC, Baker EA, Boyd RL, Caito NM, Duggan K, Housemann RA, Kreuter MW, Mitchell T, Motton F, Pulley C, Schmid TL, Walton D: A community-based approach to promoting walking in rural areas. Am J Prev Med 2004, 27:28-34.

41. Brownson RC, Hagood L, Lovegreen SL, Britton B, Caito NM, Elliott MB, Emery J, Haire-Joshu D, Hicks D, Johnson B, McGill JB, Morton S, Rhodes G, Thurman T, Tune D: A multilevel ecological approach to promoting walking in rural communities. Prev Med 2005, 41:837-842.

42. Campbell MK, Resnicow K, Carr C, Wang T, Williams A: Process evaluation of an effective church-based diet intervention: Body \& Soul. Health Educ Behav 2007, 34:864-880.

43. Davies C, Corry K, Van Itallie A, Vandelanotte C, Caperchione C, Mummery WK: Prospective associations between intervention components and website engagement in a publicly available physical activity website: the case of 10,000 Steps Australia. J Med Internet Res 2012, 14:e4

44. De Cocker KA, De Bourdeaudhuij IM, Brown WJ, Cardon GM: Effects of "10,000 steps Ghent": a whole-community intervention. Am J Prev Med 2007, 33:455-463.

45. De Cocker KA, De Bourdeaudhuij IM, Brown WJ, Cardon GM: Four-year follow-up of the community intervention'10,000 steps Ghent'. Health Educ Res 2011, 26:372-380.

46. de Jong J, Lemmink KA, King AC, Huisman M, Stevens M: Twelve-month effects of the Groningen active living model (GALM) on physical activity, health and fitness outcomes in sedentary and underactive older adults aged 55-65. Patient Educ Couns 2007, 66:167-176.

47. de Jong J, Lemmink KA, Stevens M, de Greef MH, Rispens P, King AC, Mulder T: Six-month effects of the Groningen active living model (GALM) on physical activity, health and fitness outcomes in sedentary and underactive older adults aged 55-65. Patient Educ Couns 2006, 62:132-141.

48. Dubuy V, De Cocker KA, De Bourdeaudhuij IM, Maes L, Metsu P, Van Acker R, Cardon GM: '10 000 Steps Flanders': evaluation of the state-wide dissemination of a physical activity intervention in Flanders. Health Educ Res 2013, 28:546-551.

49. Eakin EG, Mummery K, Reeves MM, Lawler SP, Schofield G, Marshall AJ, Brown WJ: Correlates of pedometer use: results from a community-based physical activity intervention trial (10,000 Steps Rockhampton). Int $J$ Behav Nutr Phys Act 2007, 4:31.

50. Estabrooks PA, Bradshaw M, Dzewaltowski DA, Smith-Ray RL: Determining the impact of Walk Kansas: applying a team-building approach to community physical activity promotion. Ann Behav Med 2008, 36:1-12.

51. French SA, Harnack LJ, Hannan PJ, Mitchell NR, Gerlach AF, Toomey TL: Worksite environment intervention to prevent obesity among metropolitan transit workers. Prev Med 2010, 50:180-185.

52. Gemson DH, Commisso R, Fuente J, Newman J, Benson S: Promoting weight loss and blood pressure control at work: impact of an education and intervention program. J Occup Environ Med 2008, 50:272-281.
53. Goetzel RZ, Baker KM, Short ME, Pei X, Ozminkowski RJ, Wang S, Bowen JD, Roemer EC, Craun BA, Tully KJ, Baase CM: First-year results of an obesity prevention program at The Dow Chemical Company. J Occup Environ Med 2009, 51:125-138.

54. Goetzel RZ, Roemer EC, Pei X, Short ME, Tabrizi MJ, Wilson MG, Dejoy DM, Craun BA, Tully KJ, White JM, Baase CM: Second-year results of an obesity prevention program at the Dow Chemical Company. J Occup Environ Med 2010, 52:291-302.

55. Jenum AK, Anderssen SA, Birkeland Kl, Holme I, Graff-Iversen S, Lorentzen C, Ommundsen Y, Raastad T, Odegaard AK, Bahr R: Promoting physical activity in a low-income multiethnic district: effects of a community intervention study to reduce risk factors for type 2 diabetes and cardiovascular disease: a community intervention reducing inactivity. Diabetes Care 2006, 29:1605-1612.

56. Jenum AK, Lorentzen CA, Ommundsen Y: Targeting physical activity in a low socioeconomic status population: observations from the Norwegian 'Romsas in Motion' study. Br J Sports Med 2009, 43:64-69.

57. Karen Jenum A, Lorentzen C, Anderssen SA, Birkeland KI, Holme I, LundLarsen PG, Ommundsen Y, Raastad T, Thelle DS, Bahr R: Promoting physical activity in a multi-ethnic district - methods and baseline results of a pseudo-experimental intervention study. Eur J Cardiovasc Prev Rehabil 2003, 10:387-396.

58. Khosravi A, Mehr GK, Kelishadi R, Shirani S, Gharipour M, Tavassoli A, Noori F, Sarrafzadegan N: The impact of a 6-year comprehensive community trial on the awareness, treatment and control rates of hypertension in Iran: experiences from the Isfahan healthy heart program. BMC CardiovasC Disord 2010, 10:61.

59. Kloek GC, van Lenthe FJ, Meertens YM, Koelen MA, Mackenbach JP: Process evaluation of a Dutch community intervention to improve health related behaviour in deprived neighbourhoods. Soz Praventivmed 2006, 51:259-272

60. Kloek GC, van Lenthe FJ, van Nierop PW, Koelen MA, Mackenbach JP: Impact evaluation of a Dutch community intervention to improve health-related behaviour in deprived neighbourhoods. Health Place 2006, 12:665-677.

61. Kwak L, Kremers SP, Candel MJ, Visscher TL, Brug J, van Baak MA: Changes in skinfold thickness and waist circumference after 12 and 24 months resulting from the NHF-NRG In Balance-project. Int I Behav Nutr Phys Act 2010, 7:26.

62. Kwak L, Kremers SP, Visscher TL, van Baak MA, Brug J: Behavioral and cognitive effects of a worksite-based weight gain prevention program: the NHF-NRG in balance-project. J Occup Environ Med 2009, 51:1437-1446.

63. Kwak L, Kremers SP, Werkman A, Visscher TL, van Baak MA, Brug J: The NHF-NRG In Balance-project: the application of Intervention Mapping in the development, implementation and evaluation of weight gain prevention at the worksite. Obes Rev 2007, 8:347-361.

64. Linde JA, Nygaard KE, MacLehose RF, Mitchell NR, Harnack LJ, Cousins JM, Graham DJ, Jeffery RW: HealthWorks: results of a multi-component group-randomized worksite environmental intervention trial for weight gain prevention. Int J Behav Nutr Phys Act 2012, 9:14

65. Lorentzen C, Ommundsen Y, Jenum AK, Holme I: The "Romsas in Motion" community intervention: program exposure and psychosocial mediated relationships to change in stages of change in physical activity. Int J Behav Nutr Phys Act 2007, 4:15.

66. Lorentzen C, Ommundsen Y, Jenum AK, Holme I: The "Romsas in Motion" community intervention: mediating effects of psychosocial factors on forward transition in the stages of change in physical activity. Health Educ Behav 2009, 36:348-365.

67. Maddock J, Takeuchi L, Nett B, Tanaka C, Irvin L, Matsuoka C, Wood B: Evaluation of a statewide program to reduce chronic disease: The Healthy Hawaii Initiative, 2000-2004. Eval Program Plann 2006, 29:293-300.

68. Matsudo SM, Matsudo VKR, Andrade DR, Araújo TL, Pratt M: Evaluation of a physical activity promotion program: The example of Agita São Paulo. Eval Program Plann 2006, 29:301-311.

69. Matsudo SM, Matsudo VR, Araujo TL, Andrade DR, Andrade EL, de Oliveira LC, Braggion GF: The Agita Sao Paulo Program as a model for using physical activity to promote health. Rev Panam Salud Publica 2003, $14: 265-272$.

70. Matsudo V, Matsudo S, Andrade D, Araujo T, Andrade E, de Oliveira LC, Braggion G: Promotion of physical activity in a developing country: the Agita Sao Paulo experience. Public Health Nutr 2002, 5:253-261. 
71. Matsudo VK, Matsudo SM, Araujo TL, Andrade DR, Oliveira LC, Hallal PC: Time trends in physical activity in the state of Sao Paulo, Brazil: 2002-2008. Med Sci Sports Exerc 2010, 42:2231-2236.

72. Mummery WK, Schofield G, Hinchliffe A, Joyner K, Brown W: Dissemination of a community-based physical activity project: the case of 10,000 steps. J Sci Med Sport 2006, 9:424-430.

73. Nigg C, Maddock J, Yamauchi J, Pressler V, Wood B, Jackson S: The healthy Hawaii initiative: A social ecological approach promoting healthy communities. Am J Health Promot 2005, 19:310-313.

74. Pegus C, Bazzarre TL, Brown JS, Menzin J: Effect of the Heart At Work program on awareness of risk factors, self-efficacy, and health behaviors. J Occup Environ Med 2002, 44:228-236.

75. Perez AP, Phillips MM, Cornell CE, Mays G, Adams B: Promoting dietary change among state health employees in Arkansas through a worksite wellness program: the Healthy Employee Lifestyle Program (HELP). Prev Chronic Dis 2009, 6:A123.

76. Phillips G, Renton A, Moore DG, Bottomley C, Schmidt E, Lais S, Yu G, Wall M, Tobi P, Frostick C, Clow A, Lock K, Petticrew M, Hayes R: The Well London program-a cluster randomized trial of community engagement for improving health behaviors and mental wellbeing: baseline survey results. Trials 2012, 13:105.

77. Rabiei K, Kelishadi R, Sarrafzadegan N, Abedi HA, Alavi M, Heidari K, Bahonar A, Boshtam M, Zare K, Sadeghi S: Process evaluation of a communitybased program for prevention and control of non-communicable disease in a developing country: The Isfahan Healthy Heart Program, Iran. BMC Public Health 2009, 9:57.

78. Rabiei K, Kelishadi R, Sarrafzadegan N, Sadri G, Amani A: Short-term results of community-based interventions for improving physical activity: Isfahan Healthy Heart Programme. Arch Med Sci 2010, 6:32-39.

79. Racette SB, Deusinger SS, Inman CL, Burlis TL, Highstein GR, Buskirk TD, Steger-May K, Peterson LR: Worksite Opportunities for Wellness (WOW): effects on cardiovascular disease risk factors after 1 year. Prev Med 2009, 49:108-114.

80. Rana AK, Wahlin A, Lundborg CS, Kabir ZN: Impact of health education on health-related quality of life among elderly persons: results from a community-based intervention study in rural Bangladesh. Health Promot Int 2009, 24:36-45.

81. Resnicow K, Campbell M, Carr C, McCarty F, Wang T, Periasamy S, Rahotep S, Doyle C, Williams A, Stables G: Body and soul. A dietary intervention conducted through African-American churches. Am J Prev Med 2004, 27:97-105.

82. Rissel CE, New C, Wen LM, Merom D, Bauman AE, Garrard J: The effectiveness of community-based cycling promotion: findings from the Cycling Connecting Communities project in Sydney, Australia. Int J Behav Nutr Phys Act 2010, 7:8.

83. Ronckers ET, Groot W, Steenbakkers M, Ruland E, Ament A: Costs of the 'Hartslag Limburg' community heart health intervention. BMC Public Health 2006, 6:51.

84. Ronda G, Van Assema P, Candel M, Ruland E, Steenbakkers M, Van Ree J, Brug J: The Dutch Heart Health community intervention 'Hartslag Limburg': results of an effect study at individual level. Health Promot Int 2004, 19:21-31.

85. Ronda G, Van Assema P, Ruland E, Steenbakkers M, Brug J: The Dutch Heart Health Community Intervention 'Hartslag Limburg': design and results of a process study. Health Educ Res 2004, 19:596-607.

86. Ronda G, Van Assema P, Ruland E, Steenbakkers M, Van Ree J, Brug J: The Dutch heart health community intervention 'Hartslag Limburg': results of an effect study at organizational level. Public Health 2005, 119:353-360.

87. Rowley KG, Daniel M, Skinner K, Skinner M, White GA, O'Dea K: Effectiveness of a community-directed 'healthy lifestyle' program in a remote Australian aboriginal community. Aust N Z J Public Health 2000, 24:136-144.

88. Sarrafzadegan N, Kelishadi R, Esmaillzadeh A, Mohammadifard N, Rabiei K, Roohafza H, Azadbakht L, Bahonar A, Sadri G, Amani A, Heidari S, Malekafzali $\mathrm{H}$ : Do lifestyle interventions work in developing countries? Findings from the Isfahan Healthy Heart Program in the Islamic Republic of Iran. Bull World Health Organ 2009, 87:39-50.

89. Sarraf-Zadegan N, Sadri G, Malek Afzali H, Baghaei M, Mohammadi Fard N, Shahrokhi S, Tolooie H, Poormoghaddas M, Sadeghi M, Tavassoli A, Rafiei M, Kelishadi R, Rabiei K, Bashardoost N, Boshtam M, Asgary S, Naderi G, Changiz T, Yousefie A: Isfahan Healthy Heart Programme: a comprehensive integrated community-based programme for cardiovascular disease prevention and control. Design, methods and initial experience. Acta Cardiol 2003, 58:309-320.

90. Schuit AJ, Wendel-Vos GC, Verschuren WM, Ronckers ET, Ament A, Van Assema P, Van Ree J, Ruland EC: Effect of 5-year community intervention Hartslag Limburg on cardiovascular risk factors. Am J Prev Med 2006, 30:237-242.

91. Siegel JM, Prelip ML, Erausquin JT, Kim SA: A worksite obesity intervention: results from a group-randomized trial. Am J Public Health 2010, 100:327-333.

92. Simoes EJ, Hallal P, Pratt M, Ramos L, Munk M, Damascena W, Perez DP, Hoehner CM, Gilbertz D, Malta DC, Brownson RC: Effects of a communitybased, professionally supervised intervention on physical activity levels among residents of Recife, Brazil. Am J Public Health 2009, 99:68-75.

93. Staten LK, Cutshaw CA, Davidson C, Reinschmidt K, Stewart R, Roe DJ: Effectiveness of the Pasos Adelante chronic disease prevention and control program in a US-Mexico border community, 2005-2008. Prev Chronic Dis 2012, 9:E08.

94. Staten LK, Scheu LL, Bronson D, Pena V, Elenes J: Pasos Adelante: the effectiveness of a community-based chronic disease prevention program. Prev Chronic Dis 2005, 2:A18.

95. Stevens M, de Jong J, Lemmink KA: The Groningen Active Living Model, an example of successful recruitment of sedentary and underactive older adults. Prev Med 2008, 47:398-401.

96. Stevens M, Lemmink KA, de Greef MH, Rispens P: Groningen active living model (GALM): stimulating physical activity in sedentary older adults; first results. Prev Med 2000, 31:547-553.

97. Van Acker R, De Bourdeaudhuij I, De Cocker K, Klesges LM, Cardon G: The impact of disseminating the whole-community project ' 10,000 Steps': a RE-AIM analysis. BMC Public Health 2011, 11:3.

98. Van Acker R, De Bourdeaudhuij I, De Cocker K, Klesges LM, Willem A Cardon G: Sustainability of the whole-community project ' 10,000 Steps': a longitudinal study. BMC Public Health 2012, 12:155

99. Wall M, Hayes R, Moore D, Petticrew M, Clow A, Schmidt E, Draper A, Lock K, Lynch R, Renton A: Evaluation of community level interventions to address social and structural determinants of health: a cluster randomised controlled trial. BMC Public Health 2009, 9:207.

100. Wen LM, Thomas M, Jones H, Orr N, Moreton R, King L, Hawe P, Bindon J, Humphries J, Schicht K, Corne S, Bauman A: Promoting physical activity in women: evaluation of a 2-year community-based intervention in Sydney, Australia. Health Promot Int 2002, 17:127-137.

101. Wilcox S, Laken M, Anderson T, Bopp M, Bryant D, Carter R, Gethers O, Jordan J, McClorin L, O'Rourke K, Parrot AW, Swinton R, Yancey A: The health-e-AME faith-based physical activity initiative: Description and baseline findings. Health Promot Pract 2007, 8:69-78.

102. Xiangyang T, Lan Z, Xueping M, Tao Z, Yuzhen S, Jagusztyn M: Beijing health promoting universities: practice and evaluation. Health Promot Int 2003, 18:107-113.

103. Gittelsohn J, Kim EM, He S, Pardilla M: A food store-based environmental intervention is associated with reduced $\mathrm{BMI}$ and improved psychosocia factors and food-related behaviors on the Navajo nation. J Nutr 2013, 143:1494-1500.

104. Raine KD, Plotnikoff R, Schopflocher D, Lytvyak E, Nykiforuk Cl, Storey K, Ohinmaa A, Purdy L, Veugelers P, Wild TC: Healthy Alberta Communities: Impact of a three-year community-based obesity and chronic disease prevention intervention. Prev Med 2013, 57:955-962.

105. Glasgow RE: What does it mean to be pragmatic? Pragmatic methods, measures, and models to facilitate research translation. Health Educ Behav 2013, 40:257-265.

106. Antikainen I, Ellis R: A RE-AIM evaluation of theory-based physical activity interventions. J Sport Exerc Psychol 2011, 33:198-214.

107. Dzewaltowski DA, Estabrooks PA, Klesges LM, Bull S, Glasgow RE: Behavior change intervention research in community settings: how generalizable are the results? Health Promot Int 2004, 19:235-245.

108. Klesges LM, Dzewaltowski DA, Glasgow RE: Review of external validity reporting in childhood obesity prevention research. Am J Prev Med 2008, 34:216-223.

109. Vuillemin A, Rostami C, Maes L, Van Cauwenberghe E, Van Lenthe FJ, Brug J, De Bourdeaudhuij I, Oppert JM: Worksite physical activity interventions and obesity: a review of European studies (the HOPE project). Obes Facts 2011, 4:479-488.

110. Blackman KC, Zoellner J, Berrey LM, Alexander R, Fanning J, Hill JL, Estabrooks PA: Assessing the internal and external validity of mobile 
health physical activity promotion interventions: a systematic literature review using the RE-AIM framework. J Med Internet Res 2013, 15:e224.

111. Sanchez M, Rabin B, Gaglio B, Henton M, Elzarrad M, Purcell P, Glasgow R: A systematic review of eHealth cancer prevention and control interventions: new technology, same methods and designs? Transl Behav Med 2013, 3:392-401.

112. Wierenga D, Engbers LH, Van Empelen P, Duijts S, Hildebrandt VH, Van Mechelen W: What is actually measured in process evaluations for worksite health promotion programs: a systematic review. BMC Public Health 2013, 13:1190.

113. Glasgow RE, Klesges LM, Dzewaltowski DA, Bull SS, Estabrooks P: The future of health behavior change research: what is needed to improve translation of research into health promotion practice? Ann Behav Med 2004, 27:3-12.

114. Green LW, Ottoson JM, Garcia C, Hiatt RA: Diffusion theory and knowledge dissemination, utilization, and integration in public health. Annu Rev Public Health 2009, 30:151-174.

doi:10.1186/s12966-014-0147-3

Cite this article as: Compernolle et al:: A RE-AIM evaluation of evidencebased multi-level interventions to improve obesity-related behaviours in adults: a systematic review (the SPOTLIGHT project). International Journal of Behavioral Nutrition and Physical Activity 2014 11:147.

\section{Submit your next manuscript to BioMed Central and take full advantage of:}

- Convenient online submission

- Thorough peer review

- No space constraints or color figure charges

- Immediate publication on acceptance

- Inclusion in PubMed, CAS, Scopus and Google Scholar

- Research which is freely available for redistribution 